Dermatology 2009;218:382-384

DOI: $\underline{10.1159 / 000182262}$

\section{Palmoplantar Pustular Lesions during Ovulation Inducement Therapy: New Insight into the Pathomechanism of Palmoplantar Pustulosis?}

Masaru Honma a ,Hidetoshi Takahashi ${ }^{a}$, Michiharu Horikawab, Hajime lizuka ${ }^{a}$

Departments of a Dermatology and ${ }^{b}$ Obstetrics and

Gynecology, Asahikawa Medical College, Asahikawa, Japan

\section{Key Words}

Buserelin acetate $\cdot$ Estradiol

Palmoplantar pustulosis (PPP) is a recurrent pustular dermatosis localized on palms and soles [1]. Although focal infections such as chronic tonsillitis, sinusitis or periodontitis have been suggested to be modifying factors in a portion of the cases, for the most part, the essential pathomechanism presently remains unknown. Female predominance has also been recognized as a factor, which suggests an association with sex hormones. We had 2 cases of PPP following ovulation inducement therapy using buserelin acetate, a GnRH agonist. These cases suggest the relation of PPP to the alteration of hormonal conditions.

\section{Case Reports}

Case 1 is that of a 33-year-old Japanese woman who presented with pustules on her palms (fig. 1A, B). The patient did not have any personal or familial history of PPP or psoriasis and laboratory findings did not indicate any abnormality in blood counts, biochemistry or thyroid function. The patient was treated for sterility and noticed skin lesions appearing after starting ovulation inducement therapy using buserelin acetate nasal spray and estrogen patches. She had, however, been smoking for several years. Buserelin acetate nasal spray was administered every day from the beginning of the high body temperature phase and the patient used estrogen patches starting at the beginning of menstruation. Skin lesions appeared 1 or 2 days after every beginning of buserelin acetate treatment but before application of the estrogen patch. Parts of the skin on which estrogen patches or buserelin acetate were applied did not show any contact dermatitis or pustules. Pustules and erythemas on the palms recurred after every usage of buserelin acetate (fig. 1C) but they did not appear on the soles. The peak number of pustules gradually decreased with repeated ovulation inducement therapy treatments (fig. 1D). These skin lesions were clinically indistinguishable from PPP. Although these lesions improved and worsened cyclically along with buserelin acetate administration, the symptoms were relatively easily controlled with a topical steroid and no arthritis associated with SAPHO syndrome was apparent during all courses.

Case 2 is that of a 34-year-old Japanese woman who presented with pustules on her palms and soles (fig. 1E). She noticed persistent palmar pustules and vesicles about a month after the administration of buserelin acetate. Although she had also been smoking for several years, she had never experienced palmoplantar lesions until this time. The administration protocol of buserelin acetate and an estrogen patch was the same as that in case 1 . Her lesions were recalcitrant to topical steroid, topical maxacalcitol and topical PUVA treatments. The condition improved slightly after the cessation of buserelin acetate (fig. 1F). The parts of the skin on which estrogen patches or buserelin acetate were applied did not show any contact dermatitis or pustules and the patient did not have any personal or familial history of PPP or psoriasis just as in case 1 . Signs of arthritis suggesting SAPHO syndrome did not appear during all courses.

\section{Discussion}

PPP, which is considered a palmoplantary localized pustular dermatosis, is relatively common especially in middle-aged smoking women $[1,2]$. Although its relation to focal bacterial infection is known, the treatment of focal infection occasionally improves skin lesions in limited cases. Recently, metal allergy has also been suggested as a cause of PPP [3]. In addition, genetics has been identified as a factor. In both cases reported here, there was a history of smoking, yet there were no other past skin diseases.

Although both patients received ovulation inducement therapy using buserelin acetate and estradiol in our cases, skin lesions appeared only several days after usage of buserelin acetate but before application of the estrogen patch. In addition, there were no signs of contact dermatitis on the parts of the skin where both agents were administered. These facts indicate that the skin lesion could be mainly associated with buserelin acetate via hormonal or immunological mechanisms other than an allergic response. In psoriasis, the association between sex steroid and skin lesions has been reported $[4,5]$. Previous reports have indicated a positive correlation between the estrogen/progesterone ratio and the improvement of psoriasis during pregnancy [6]. On the other hand, it is also known that tamoxifen, an anti-estrogen agent, improves psoriatic arthritis [5]. Buserelin acetate, a GnRH analogue, inhibits release of estrogen and progesterone via downregulation of GnRH receptor in long-term administration. Nevertheless, in the early phase, it leads to transient estrogen release known as a flareup phenomenon following the ovulation inducement therapy [7]. TNF- $\alpha$, one of the inflammatory cytokines, is known to be involved in the pathogenesis of inflammatory skin disorders in-

\section{KARGER}

(C) 2008 S. Karger AG, Basel

Fax +41613061234 E-Mail karger@karger.ch www.karger.com 

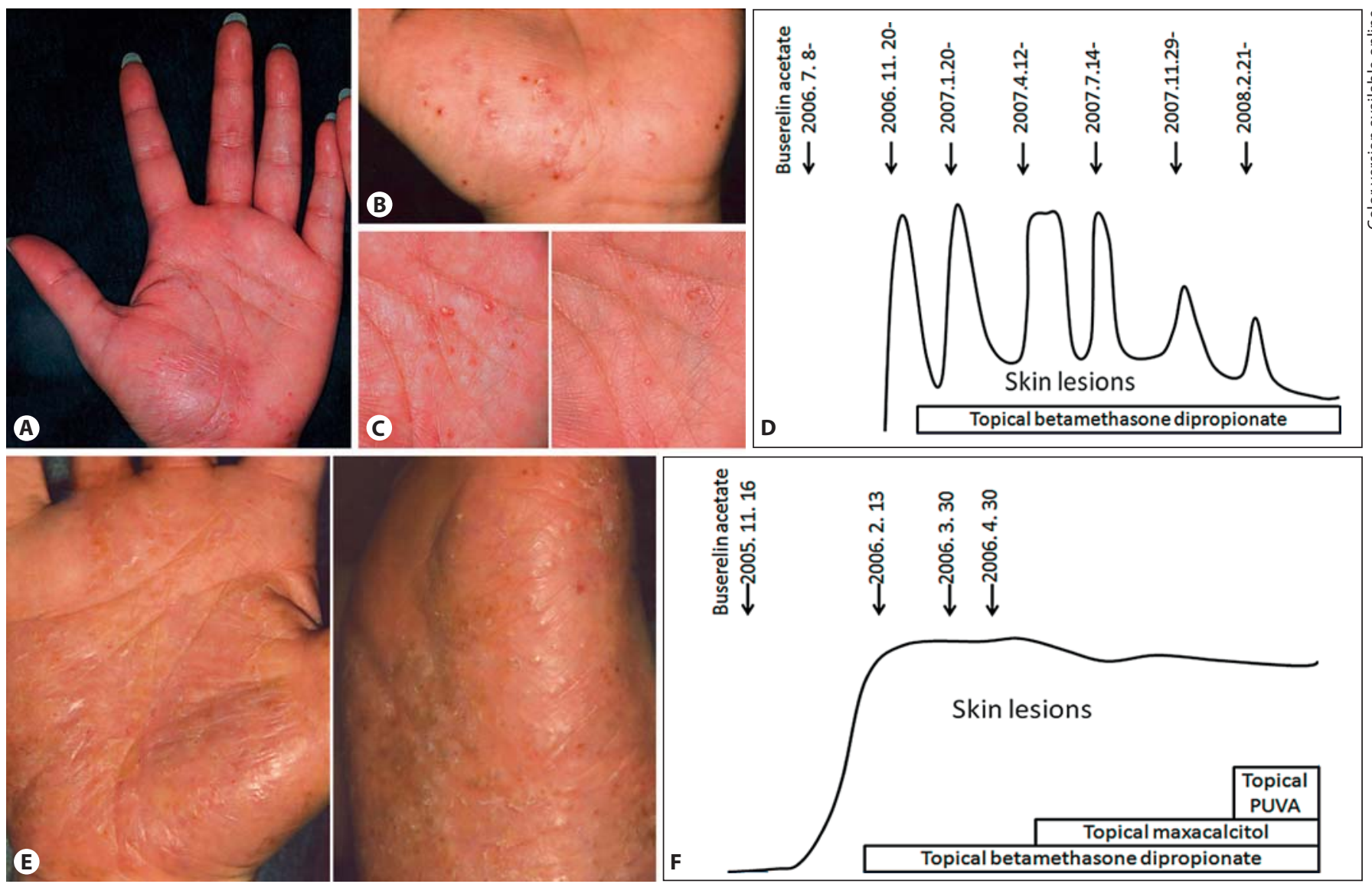

Fig. 1. Clinical observation of case 1: Erythemas and pustules mainly localized on the bilateral thenars. Pustules on thenar and hypothenar. Although palmer pustules increased along with administration of buserelin acetate (upper panel), these pustules decreased after the cessation of buserelin acetate (lower panel). Clinical course of case 1: The skin lesions altered cyclically along with

every buserelin acetate administration. Clinical feature of case 2: Scaly erythema with pustules localized on palms and soles, especially thenars and plantar arches. Clinical course of case 2: The skin lesions were quite persistent despite various treatments and they never fully disappeared.

cluding PPP $[8,9]$ and psoriasis. The level of serum TNF- $\alpha$ fluctuates during the menstrual cycle and it is at the peak around days 7-9 of the cycle [10]. Also, the association between $\mathrm{GnRH}$ and TNF- $\alpha$ has been identified [11]. In addition, Babayof et al. [12] reported that the serum level of TNF- $\alpha$ is upregulated transiently during GnRH administration. Furthermore, psoriasiform eruption after administration of an anti-TNF- $\alpha$ agent, so-called paradoxical adverse reaction, has been reported [13-15]. The appearance of these skin lesions usually cycles along with the administration of anti-TNF- $\alpha$ agent. However, in a few cases, these eruptions persist even after cessation of anti-TNF- $\alpha$ agent [1315]. The differences in the clinical features between case 1 and case 2 may be linked to this phenomenon. Although the pathomechanism of PPP is still unclear, our 2 cases suggest hormonal factors may be significantly involved in PPP. Hormonal circumstances might explain the female predominance of PPP and the periodically worsening of PPP symptoms, which may lead new insight into this disease's pathogenesis and treatment.

\section{References}

1 Christophers E, Mrowietz U: Pustular eruptions of palms and soles; in Freedberg IM, Eisen AZ, Wolff K, Austen KF, Goldsmith LA, Katz SI (eds): Dermatology in General Medicine. New York, McGraw-Hill, 2003, vol I, pp 628-631.

2 Bø K, Thoresen M, Dalgard F: Smokers report more psoriasis, but not atopic dermatitis or hand eczema: results from a Norwegian population survey among adults. Dermatology 2008;216:40-45.

-3 Yanagi T, Shimizu T, Abe R, Shimizu H: Zinc dental fillings and palmoplantar pustulosis. Lancet 2005;366:1050.

4 Kanda N, Watanabe S: Regulatory roles of sex hormones in cutaneous biology and immunology. J Dermatol Sci 2005;38:1-7.

5 Stevens HP, Ostlere LS, Black CM, Jacobs HS, Rustin MH: Cyclical psoriatic arthritis responding to anti-oestrogen therapy. $\mathrm{Br}$ J Dermatol 1993; 129:458-460.

6 Murase JE, Chan KK, Garite TJ, Cooper DM, Weinstein GD: Hormonal effect on psoriasis in pregnancy and post partum. Arch Dermatol 2005;141:601-606. 
7 Ortmann O, Weiss JM, Diedrich K: Embryo implantation and GnRH antagonists: ovarian actions of GnRH antagonists. Hum Reprod 2001; 16:608-611.

8 Hashigucci K, Niizeki H, Naruse T, Ota M, Inamoto N, Nishikawa T, Inoko H: A clinical feature associated with polymorphisms of the TNF region in Japanese patients with palmoplantar pustulosis. Hum Immunol 2003;64:530-537.

-9 Murakata H, Harabuchi Y, Kataura A: Increased interleukin-6, interferon- $\gamma$ and tumour necrosis factor- $\alpha$ production by tonsillar mononuclear cells stimulated with $\alpha$-streptococci in patients with pustulosis palmaris et plantaris. Acta Otolaryngol 1999;119:384-391.

10 Macewan DJ: Interactions between TNF and GnRH. Neurochem Res 2008;33:678-682.

11 Brännström M, Fridén BE, Jasper M, Norman RJ: Variations in peripheral blood levels of immunoreactive tumor necrosis factor $\alpha$ (TNF- $\alpha)$ throughout the menstrual cycle and secretion of TNF- $\alpha$ from the human corpus luteum. Eur J Obstet Gynecol Reprod Biol 1999;83:213217.

-12 Babayof R, Margalioth EJ, Huleihel M, Amash A, Zylber-Haran E, Gal M, Brooks B, Mimoni T, Eldar-Geva T: Serum inhibin A, VEGF and TNF- $\alpha$ levels after triggering oocyte maturation with $\mathrm{GnRH}$ agonist compared with HCG in women with polycystic ovaries undergoing IVF treatment: a prospective randomized trial. Hum Reprod 2006;21: $1260-1265$.
13 De Gannes GC, Ghoreishi M, Pope J, Russell A, Bell D, Adams S, Shojania K, Martinka M, Dutz JP: Psoriasis and pustular dermatitis triggered by TNF- $\alpha$ inhibitors in patients with rheumatologic conditions. Arch Dermatol 2007; 143:223-231.

14 Takahashi H, Hashimoto Y, Ishida-Yamamoto A, Ashida T, Kohgo Y, Iizuka H: Psoriasiform and pustular eruption induced by infliximab. J Dermatol 2007;34:468-472.

15 Passarini B, Infusino SD, Barbieri E, Varotti E, Gionchetti P, Rizzello F, Morselli C, Tambasco R, Campieri M: Cutaneous manifestations in inflammatory bowel diseases: eight cases of psoriasis induced by antitumor-necrosis-factor antibody therapy. Dermatology 2007;215:295300.

Masaru Honma, MD, PhD

Department of Dermatology, Asahikawa Medical College Midorigaoka-Higashi 2-1-1-1, Asahikawa (Japan)

Tel. +81 16668 2523, Fax +81 166682529

E-Mailwanwan@asahikawa-med.ac.jp 